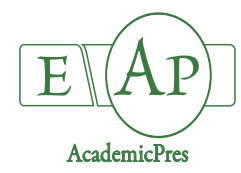

El-Beltagi HS et al. (2020)
Notulae Botanicae Horti Agrobotanici Cluj-Napoca 48(4):1941-1956
DOI:10.15835/48412151
Research Article

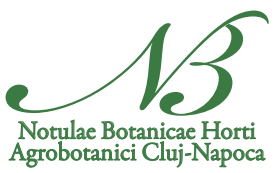

\title{
Antioxidant, anti-cancer and ameliorative activities of Spirulina platensis and pomegranate juice against hepatic damage induced by $\mathrm{CCl} 4$
}

\author{
Hossam S. EL-BELTAGI ${ }^{1,2 *}$, Faten DHAWI ${ }^{1}$, Ihab S. ASHOUSH ${ }^{3}$, \\ Khaled M. A. RAMADAN ${ }^{4,5}$
}
${ }^{1}$ King Faisal University, Agricultural Biotechnology Department, College of Agriculture and Food Sciences, P.O. Box 420, Al-Ahsa 31982,Saudi Arabia; helbeltagi@kfu.edu.sa (*correspondingauthor); falmuhanna@kfu.edu.sa
${ }^{2}$ Cairo University, Faculty of Agriculture, Biochemistry Department, Gamma st, Giza, P.O. 12613, Egypt
${ }^{3}$ Ain Shams University, Faculty of Agriculture, Food Science Department, Cairo, Egypt; Ihab.ashoush@gmail.com
${ }^{4}$ King Faisal University, Central Laboratories, Kingdom of Saudi Arabia; kramadan@kfu.edu.sa
${ }^{5}$ Ain-Shams University, Faculty of Agriculture, Agricultural Biochemistry Department, Cairo, Egypt

\begin{abstract}
Due to the excessive impact of synthetic drugs, unravelling and employing safe, natural alternatives are now needed to resolve a number of diseases. In this research, we have evaluated hepatoprotective and antioxidant activities of Spirulina platensis and pomegranate juice in rats against hepatotoxicity induced by carbon tetrachloride (CCl4). Spirulina crude carotenoid extract was screened by UPLC-MS / MS. Activities of liver marker enzymes; measured aspartate aminotransferase (AST) and alanine aminotransferase (ALT), and determined lipid peroxidation and antioxidant status as reduced glutathione (GSH) in liver homogenate. The infusion of CCl4 ( $2 \mathrm{ml} / \mathrm{kg}$ b.wt) greatly increases levels of liver marker enzymes and lipid peroxidation, resulting in depletion of antioxidants. Treatment of Spirulina platensis $(\mathrm{Sp})$, pomegranate juice $(\mathrm{Pj})$ or mixture (PJSP) of Spirulina water extract 10\% and pomegranate juice $90 \%(1 \mathrm{ml} / 100 \mathrm{~g} \mathrm{~b} . w \mathrm{t})$ to CCl4-disrupted rats resulted in decreased activity of liver marker enzymes, lipid peroxidation with increased antioxidant status. Chromatographic separation showed that $\beta$-carotene is the predominant carotenoid extract. This carotenoid extract was tested for colon carcinoma (HCT-116), liver carcinoma (HepG2) and intestinal carcinoma cell lines (CACO) LC50 for 21.8, 14 and $11.3 \mathrm{ug} / \mathrm{ml}$, respectively. Total phenolic phytochemicals, total carotenoids and total flavonoids were also measured in Spirulina. Our study clearly demonstrates that Spirulina platensis and pomegranate juice had hepatoprotective effect on CCl4-caused hepatotoxicity in rats through its antioxidant activity.
\end{abstract}

Keywords: anticancer; antioxidant status; carotenoids; liver injury; pomegranate juice; Spirulina platensis 


\section{Introduction}

Liver is recognized to be one of the largest and most important organs in human biological system because of its pivotal role in metabolism, detoxification and excretion. It also performs an astounding role in maintenance, performance and regulation of homeostasis in biological system engaged in major biochemical growth pathways and all other biological activities (Ward and Daly, 1999). Carbohydrates, protein and lipid metabolism, detoxification, bile salt secretion, and vitamin storage are main functions of liver. Liver is constantly and variedly subjected to environmental contaminants and is impaired by unsafe medications, alcohol practices and an over-the-counter drug that can ultimately lead to numerous liver diseases, such as hepatitis, cirrhosis, liver disease (Subramonium and Pushpangadan, 1999). For now, the liver diseases are some of critical diseases in the world (Asrani et al., 2019). Hence it poses significant threat to human health all over the world. However, conventional treatments have little effect on the elevation of hepatic diseases and are primarily natural preparations used for treatment of liver diseases (Karan et al., 1999; Chaterrjee, 2000; AbdelRahim et al., 2010; Abd El-Maksoud et al., 2018). Hence, in the experimental animal model, several traditional herbal medicines are investigated for their possible hepatoprotective and antioxidant liver damage.

Spirulina platensis is blue-green, fresh water algae commonly used as a nutritional supplement. There are abundant proteins, carotenoids, essential fatty acids, vitamin B, vitamin E, and minerals, like copper, manganese, magnesium, iron, selenium, zinc. Spirulina platensis has gained significant popularity not only for its high nutritive quality; it's really signs of strong antioxidants like spirulans (sulfate polysaccharides), selenocompounds, phenolic compounds, phycobiliproteins (C-phycocyanin and allophycocyanin) (Konícková et al., 2014). Spirulina's macronutrient profile has more than $60 \%$ protein with 22 essential amino acids known to be of high biological significance, C-phycocyanin and allophycocyanin proteins were the focus of extensive Spirulina studies (Yoshikawa, 2008; de Cruz et al., 2018). It has profile of high-quality fatty acids (Omega-6 and gamma-linoleic acid). Spirulina as well includes valuable antioxidant, probiotic and nutraceutical phytonutrients (Soni et al., 2017). Hypolipidemic, hypocholesterolemic and antioxidant effects as well as neuroprotective and immunomodulatory roles have been correlated with Spirulina consumption (Serban et al., 2015; Finamore et al., 2017). In addition, its intake was correlated with reduction in age-related cerebellar tumor necrosis factors (TNF-5-007), $\beta$ (TNF- $\beta$ ) and increment in function of the $\beta$-adrenergic receptor. Several reports indicated that metabolites generated by Spirulina found to inhibit the replication of different human viruses (Rechter et al., 2006). Spirulina extracts have also been identified as antimicrobials and anticancer agents (El-Baz et al., 2013; Czerwonka et al., 2018). Numerous studies have tested Spirulina's antioxidant effects and capacity to scavenge hydroxyl radicals and prevent lipid peroxidation (Dartsch, 2008). Spirulina species displayed a number of biological behaviours, such as antihypertensive and antihyperilemic (Torres-Duran et al., 2007). Chemopreventive agent for cancer and hepatoprotective agent for heavy metal toxicity (Ismail et al., 2009; Karadeniz et al., 2009). Spirulina fusiformis has shown hepatoprotection towards oxidative stress mediated by mercury chloride (Sharma et al., 2007).

Pomegranate (Punica granatum), which grows wildly in Mediterranean countries and is usually consumed as fresh fruit or beverage, has long been of interest due to its beneficial health effects. Pomegranate juice and shell have a marked antioxidant effect. Pomegranate juice consists of water (85\%), sugar (10\%), pectin, ascorbic acid, polyphenols (1.5\%) (Aviram et al., 2000). Beneficial impacts of pomegranate juice on human health are thought to have a significant antioxidant effect (Balasundram et al., 2006; Rosenblat et al., 2006; Laura Marín et al., 2015). Pomegranate juice contains anthocyanins (delphinidine-3-glucosidase, delphinidine-3.5 glucosidase, cyanidin and pelargonidine) and ellagitanins ( $2 \mathrm{~g} / \mathrm{L}$ as polyphenol) which scavenge free radicals and reduce their deleterious effects. Antioxidant efficiency of pomegranate belongs to Punicalagin, which is the main ellagitannine. It is rich in flavonoids (quercetin, kaemferol and luteol) glycosides and polyphenolic acids (elaic and galic) acid (Lansky, 2006; Abdel-Rahim et al., 2013). Pomegranate juice's extracellular antioxidant efficacy was shown to be three times higher compared to green tea and 2-6 times greater compared to other natural beverages (Seeram et al., 2005). Pomegranate juice has recently been shown 
to be responsible for increasing antioxidant defense mechanisms and to have a protective impact in testicular tissue toward CCl4-caused acute toxicity in rats (Al-Olayan et al., 2014). In another study, pomegranate juice intake increased glutathione levels, and reduced lipid and protein oxidation. Since antioxidant mechanisms and glutathione level play a significant role in PCT-related hepatic damage, these studies suggest that pomegranate juice may have preventive or therapeutic effects in terms of hepatic toxicity (Matthaiou et al., 2014).

Carotenoids interact strongly with reactive oxygen species and work as efficient free radical quenchers, singlet oxygen scavengers, lipid antioxidants (some which are precursors of vitamin $\mathrm{A}$ ) in plant and animal organisms (Aly et al., 2012; Helmi and Mohamed, 2016; Mohamed and Akladious, 2017; Akladious and Mohamed, 2017). Apart from this physiological and medical significance, shifts in carotenoid content and structure may also serve as indicators of environmental harm (Ladislav et al., 2005; Marzorati et al., 2020). Additionally, chemical structure of carotenoids is a long, aliphatic, conjugated double bond system, i.e. polyene. Aspect of these are $\mathrm{C} 40$ hydrocarbons, generally consisting of eight isoprene units. Many natural carotenes in an all-trans position have double bonds, where $\mathrm{R}$ is open-chain structure or ring network. Only a handful of known carotenes have cis-trans structure. Further member of carotenoid group is a number of oxygenated carotene derivatives combinations such as hydroxyl, epoxy, alcohol, aldehyde, ketone, lactone, carboxylic, ester, phenolic. Such compounds are named xanthophyll. Several studies have shown that the intake of dietary carotenoids is connected to prevention of debilitating diseases like cancer, atherosclerosis and age-related macular degeneration in humans due to their ability to suppress oxidative lesions by scavenging free radicals and extracting singlet oxygen. Many carotenoid biological activities have also been reported, such as immune enhancement, anti-inflammation, and anti-obesity (Bernal, 2011; Nagao, 2014). In Chlorella vulgaris, carotenoids are $\beta$-carotene, lutein and astaxanthin whereas in Spirulina platensis, they are $\beta$-carotene, lutein, and zeaxanthin. Nearly $85 \%$ of primary liver tumors account for hepatocellular carcinoma (Kew, 2002). Hepatocellular carcinoma is world's fifth most prevalent malignancy, and world's third most prevalent cancerrelated manner of death (Kew, 2002). Cancer is triggered by cell proliferation and apoptosis or death factor imbalances. Apoptosis may affect growth of tumors at one or more cancerous phases. Apoptosis is type of programmed cell death defined by morphological changes in cells caused by cysteine-aspartate proteases (caspases) and controlled by BCl-2 family of proteins. Implied in signal propagation (Hanson et al., 2008). A strong chemopreventive agent is naturally present agent, which may cause apoptosis in cancer cells without side effects (Surh, 1999).

Purpose of this investigation was to assess ability of Spirulina and pomegranate towards CCl4-induced hepatic intoxication in adult male rats in an attempt to understand their mechanism of action, antioxidant activity of the components of Spirulina and pomegranate and preventive role against oxidative stress and hepatic harm, as well as profile of Spirulina carotenoids and their anti-tumor activity, which may give lighter shade to the possibility of using it for therapeutic nutrition.

\section{Materials and Methods}

\section{Materials and chemicals}

Pomegranate (Punica granatum L.) fruits were purchased from local market, Cairo, Egypt. Whereas, spirulina (Spirulina platensis) biomass was obtained from Algae Biotechnology Unit, National Research Center, Giza, Egypt.

Commercial kits used for the determination of alanine aminotransferase (ALT); aspartate aminotransferase (AST); malondialdehyde (MDA) and reduced glutathione (GSH) were purchased from Biodiagnostic Co. Dokki, Egypt. Whereas carbon tetrachloride (CCl4) has been obtained from El-Gomhoreya Co, Cairo, Egypt. Meanwhile, 2,2-diphenyl-2-picrylhydrazile radical (DPPH) was purchased from Sigma Aldrich Inc. (St Louis, MO, USA). 


\section{Pomegranate juice preparation}

Pomegranate fruits $(2.5 \mathrm{Kg})$ were washed and drained by tap water. The pomegranate fruit was sliced manually and outer leathery skin, which encloses hundreds of fleshy bags, was removed. Juice in bags was extracted using a domestic squeezer (Kenwood juicer, USA); juice obtained was stored under freezing conditions $\left(-20^{\circ} \mathrm{C}\right)$ until it was used and analysed (Maskan, 2006).

\section{Spirulina aqueous extract preparation}

Aqueous extract of biomass from Spirulina (Spirulina platensis) was prepared using described method (Abdel-Salam et al., 2015). Spirulina platensis materials $(250 \mathrm{~g})$ were pulverized separately in a grinder $(6 \%$ gross dry matter) for a short period. Then, pulverized content was dissolved and processed in electric blender one time for $15 \mathrm{~min}$ with $1000 \mathrm{ml}$ of hot distilled water $\left(50-55^{\circ} \mathrm{C}\right)$. Suspension remained for one hour at room temperature, then filtered twice, first through the cheesecloth ( $50 \%$ cotton $/ 50 \%$ polyester) and then through filter paper (Whatman No. 2). Until further usage clear aqueous extract was stored in sterile dark bottles (100 $\mathrm{ml})$ at $-20^{\circ} \mathrm{C}$.

\section{Preparation the combination of pomegranate juice and Spirulina extract (PJSP)}

Five separate blends of pomegranate juice and Spirulina aqueous extract were freshly prepared in varying proportions from the mixture of pomegranate juice (PJ): Spirulina aqueous extract (SP) as follows: 50:50, 60:40, 70:30, 80:20 and 90:10 \%; then the sensory assessment was carried out by ten semi-trained panelists from the Ain Shams University Department of Food Science Staff; which revealed that the proportion of blends PJ: SP in ratio 90:10 was most preferred for consumption by the panelists in comparing to other blending ratios.

\section{DPPH radical scavenging activity}

Capacity of extract samples to scavenge 2,2-diphenyl-2-picrylhydrazile (DPPH) free radicals has been calculated using described method (Brand-Williams et al., 1995). Percentage of scavenging effect was measured according to following equation from the reduction of absorbance at $517 \mathrm{~nm}$ toward the control:

Scavenging operation percentage $=[($ Abs control - Abs sample $) /$ Abs control $] \times 100$

\section{Biological experiment design}

Experiment was carried out on thirty male Albino Wistar rats from Organization of Biological Products and Vaccines (Helwan Farm, Cairo, Egypt) with average weight of $140 \pm 10$ g; they were kept in special cages under controlled conditions. In compliance with the guidelines of AIN-93, animals were fed on basal diet and provided with ad-libitum water during experimental period (Reeves et al., 1993). For each group, rats were randomly divided into five groups of six rats each. Class one was reserved for normal control (NC). Intraperitoneal (IP) injection with single dose of $2 \mathrm{ml} / \mathrm{kg}$ body weight was administered by mixture of $(1: 1 \mathrm{v} /$ v CCl4 / paraffin oil) to groups of two to five rats (Małgorzata et al., 2009). Group 2 was maintained as injury control (IC); each rat from group 3 to group 5 received its corresponding weight dose (depending on the weight of 15 days) through oral gavage for pomegranate juice (PJ); Spirulina aqueous extract (SP) and a combination of pomegranate juice and Spirulina aqueous extract (PJSP) at dose of $1 \mathrm{ml} / 100 \mathrm{~g}$ body weight per day for period of 28 days. The estimate was based on human consumption of $275 \mathrm{ml}$ per day for $70 \mathrm{~kg}$ as recorded (Rouanet et al., 2010). Weekly shifts in body weight were detected, blood samples were collected from retro-orbital eye plexus of all rats in each group a trend of experiment; the liver was removed from the body immediately after weight bleeding. Plasma was obtained by centrifugation at $1500 \mathrm{rpm}$ for analysis at an ambient temperature for $15 \mathrm{~min}$ from blood samples. Experiment was performed in compliance with the guidelines for animal experiments of the Ain Shams University College of Agriculture. The experimental method had been approved by the Ain Shams University Ethical Committee. 
Evaluation of liver function

Activities of alanine aminotransferase (ALT) and aspartate aminotransferase (AST) were spectrometry measured using process used by Reitman and Frankel (1957).

Marker of oxidative stress

Plasma lipid peroxidation was measured using thiobarbituric acid reactive substances (TBARS) method measuring malondialdehyde (MDA) formation at $534 \mathrm{~nm}$ (Ohkawa et al., 1979). Whereas plasma reduced glutathione (GSH) has reacted with dithio - bis-2-nitrobenzoic acid (DTNB) (Beutler et al., 1963).

\section{Phytochemical evaluation of Spirulina}

Total phenolics was measured spectrophotometrically (Thermo-Fischer evolution 300-USA) (Sanoner et al., 1999), total carotenoids, HPLC Agilent 1200 equipped with diode array detector (Zhang and Omaye, 2001) and total flavonoids, spectrophotometrically (Thermo-Fischer evolution 300-USA) (Djeridane et al., 2006) were measured in Spirulina extracts according to the described methods.

\section{Preparation of Spirulina carotenoids extract}

Crude carotenoid extract was obtained by extracting $10 \mathrm{~g} \mathrm{~S}$. platensis with $250 \mathrm{ml}$-hexane: methanol (1:1) overnight at average room temperature (Subagio et al., 1996). Ten $\mathrm{ml}$ of $40 \%$ of $\mathrm{KOH}$ methanol was added to saponification mixture at room temperature overnight. After filtering with $0.45 \mu \mathrm{m}$ Teflon membrane, extract was moved to separate funnel, washed 3 times with distilled water and evaporated in a rotary evaporator at a reduced pressure of $30^{\circ} \mathrm{C}$, then carotenoids were weighed and re-dissolved in $85 \%$ ethanol.

\section{UPLC-MSMS identification of Spirulina carotenoids content}

Extracted carotenoids from $S$. platensis was investigated by Waters, Acquity-H class system UPLC-MS / MS, configured with a Xevo-TQD triple quadrupole mass spectrometer with ESI-API source (Waters, USA). Data acquisition was carried out using Mass lynx V. 4.1 software. Separation was performed by BEH C18 column $(50 \mathrm{~mm} \mathrm{X} 2.1 \mathrm{~mm}, 1.7 \mu \mathrm{m}$ by gradient solvent method acetonitrile-water-methylene chloride, flow rate $0.8 \mathrm{ml} \mathrm{min}^{-1}$. Recognition of different carotenoids in $S$. platensis was performed by comparison of mass with Mass Lynx collection.

Measurement of the possible cytotoxicity of Spirulina by Sulfo-Rhodamine-B. Assay Stain (SRB)

Possible cytotoxicity of extract has been tested using (Skehan and Storeng, 1990) method. Cells were plated in 96-multi-well plate ( 104 cells/well) for $24 \mathrm{~h}$ before compound treatment to enable cell to be attached to the plate wall. With each individual dose, specific concentrations of carotenoid extract of Spirulina under test $(0,5,12,25$ and $50 \mu \mathrm{g} / \mathrm{ml})$ were applied to monolayer triplicate well cells. Monolayer cells were incubated at $37^{\circ} \mathrm{C}, 5 \% \mathrm{CO}$. Cells were fixed, washed, stained with stain from Sulfo-Rhodamine-B (SRB) after $48 \mathrm{~h}$. Excess stain was rinsed with acetic acid and attached stain was recovered with Tris EDTA buffer. ELISA reader determined density of colours. The relation of the remaining fraction of carotenoid algal concentrated extract. After the mentioned compound is plotted survival curve of each tumour cell line. Study was applied to following lines of tumour cells:

Colon cell carcinoma line (HCT-116)

Liver cell carcinoma line (HepG2)

Cell line of intestinal carcinoma (CACO)

\section{Statistical analysis}

Data descriptive values were presented as Mean \pm SE, statistically analysed using ANOVA one-way variance analysis followed by Duncan test. In all cases the SAS program used $\mathrm{p}<0.05$ as the statistical significance criterion (SAS, 2003). 


\section{Results and Discussion}

\section{Scavenging activity of pomegranate juice; Spirulina extract and their combination}

The results of scavenging activity of the experimental materials are presented in Table (1). The results showed an increase in antioxidant activity in PJ followed by SP. While, the combination PJSP recorded the highest antioxidant activity, which revealed highly fight free radical activity $98.12 \%$. Such results are consistent with those obtained for Spirulina (Remziye et al., 2013), with high antioxidant potential due to presence of phycocyanin and phenolic compounds. It was proposed that overall peroxyl scavenging activity of Spirulina extracts shows a nearly linear association between antioxidant activity and concentration of Spirulina extract (Konícková et al., 2014). The biological value of verified was in vivo antioxidant potential, which revealed a significant improvement in Spirulina-fed rats' antioxidant ability for 5 days $(132 \pm 22$ percent, $\mathrm{p}=0.002)$. Results for pomegranate juice also confirmed by (Akram et al., 2016) showing that the radical scavenging behaviour of pomegranate juice is substantially greater. Pomegranate fruit juice contains significant amounts of organic acids, vitamins and polyphenols in the form of flavonoids that have antioxidant effects (Jaiswal et al., 2010).

Table 1. Scavenging activity \% of pomegranate juice; Spirulina extract and their combination

\begin{tabular}{|c|c|}
\hline Treatments & Scavenging activity \% \\
\hline Pomegranate juice (PJ) & $91.93 \pm 0.84^{\mathrm{b}}$ \\
\hline Spirulina extract (SP) & $71.09 \pm 0.26^{\mathrm{c}}$ \\
\hline Combination (PJSP) & $98.12 \pm 0.23^{\mathrm{a}}$ \\
\hline
\end{tabular}

Data are mean $\pm S E, n=3$, uppercase letters in column represent statistically significant data at $5 \% .{ }^{*}$ Pomegranate juice

(PJ) 90: Spirulina extract (SP) 10

\section{Body weight gain and liver ratio in rats' groups}

Even so, initial body weight of all rats was not substantially different after 28 days of feeding; in the hepatic injury control group (IC) administered with CCl4 body weight gain, it was marginally lower compared with normal control and other treatment groups (Table 2). In the other side, injured control rats treated with oral pomegranate juice (PJ), Spirulina extract (SP), and their combination (PJSP) significantly increased in weight gain relative to normal control and $\mathrm{CCl} 4$ treatment groups. With a higher increase in body weight gain compared to IC, it is presumed that treatments used with PJ, SP and their combination may boost appetite and increase weight gain. It can be seen from the same table that oral treatment of pomegranate juice (PJ), spirulina extract $(\mathrm{SP})$ or their combination $(\mathrm{PJSP})$ effectively lowered the liver ratio $(\mathrm{P}<0.05)$ relative to the IC group.

Table 2. Effects of pomegranate juice; Spirulina extract and their combination on body weight gain, liver ratio in rats

\begin{tabular}{|c|c|c|c|c|c|}
\hline Parameters & NC $^{*}$ & IC $^{*}$ & PJ & PS & PJSP \\
\hline \multicolumn{7}{|c|}{ Body weight $(\mathrm{g})$} \\
\hline Initial & $148.4 \pm 2.4^{\mathrm{a}}$ & $140.3 \pm 2.1^{\mathrm{a}}$ & $146.2 \pm 2.9^{\mathrm{a}}$ & $141.9 \pm 2.1^{\mathrm{a}}$ & $149.8 \pm 3.1^{\mathrm{a}}$ \\
\hline Final & $208.3 \pm 3.2^{\mathrm{b}}$ & $178.6 \pm 2.7^{\mathrm{c}}$ & $212.4 \pm 1.9^{\mathrm{b}}$ & $215.1 \pm 1.7^{\mathrm{b}}$ & $226.6 \pm 2.2^{\mathrm{a}}$ \\
\hline Gain & $59.9 \pm 2.3^{\mathrm{b}}$ & $38.3 \pm 3.2^{\mathrm{c}}$ & $66.2 \pm 2.8^{\mathrm{b}}$ & $73.2 \pm 1.8^{\mathrm{a}}$ & $76.8 \pm 1.5^{\mathrm{a}}$ \\
\hline \multicolumn{6}{|c|}{ Liver ratio $(\mathrm{g} / 100 \mathrm{~g} \mathrm{BW})$} \\
\hline
\end{tabular}

Data are mean \pm SE, $n=6$, uppercase letters in same raw represent statistically significant data at $5 \%$. Normal control group; "Injury control group, Pj: injured control rats treated with oral pomegranate juice, PS: injured control rats treated with Spirulina extract, PJSP: injured control rats treated with the combination between oral pomegranate juice $90 \%$ and Spirulina extract $10 \%$. 


\section{Liver function markers}

The liver plays a significant role as a main organ to detox our body from a toxicant. The current study focused on the role of pomegranate juice (PJ), spirulina extract (SP) and its combination (PJSP) against hepatic injury induced by $\mathrm{CCl}_{4}$ and on finding possible hepatoprotection.

Rats exposed to $\mathrm{CCl}_{4}$ produced substantial hepatocellular injury as shown by the higher plasma level of AST and ALT compared to normal control group and other treatment groups; also, oral administration of pomegranate juice (PJ), spirulina extract (SP) and its combination (PJSP) also showed a substantial reduction compared to the liver injury management group of rats (Table 3). As these enzymes are stored in cytoplasmic region of cell and released into circulation in event of cell damage increased plasma of hepatic markers has been associated with liver injury (Manal, 2011). Some studies have shown that spirulina (García-Martínez et al., 2007; Dartsch, 2008) significantly improves the liver markers after receiving gradient doses of Spirulina. Pomegranate juice (Faria et al., 2007; Nirwane and Patil, 2012; Sadia et al., 2016) also showed a substantial decrease in AST and ALT in rats suffering from CCl4 induced liver damage when fed with pomegranate fruit juice.

Table 3. Liver functions of different experimental groups

\begin{tabular}{|c|c|c|}
\hline Groups & AST $(\mathrm{U} / \mathrm{L})$ & ALT $(\mathrm{U} / \mathrm{L})$ \\
\hline $\mathrm{NC}^{*}$ & $49.82 \pm 3.2^{\mathrm{c}}$ & $45.19 \pm 2.1^{\mathrm{b}}$ \\
\hline $\mathrm{IC}^{* *}$ & $108.22 \pm 2.8^{\mathrm{a}}$ & $126.03 \pm 2.5^{\mathrm{a}}$ \\
\hline PJ & $58.71 \pm 1.27^{\mathrm{b}}$ & $48.04 \pm 1.7^{\mathrm{b}}$ \\
\hline SP & $57.16 \pm 1.29^{\mathrm{b}}$ & $47.22 \pm 5.8^{\mathrm{b}}$ \\
\hline PJSP & $56.13 \pm 0.8^{\mathrm{b}}$ & $44.88 \pm 3.2^{\mathrm{b}}$ \\
\hline
\end{tabular}

Data are mean \pm SE, $n=6$, uppercase letters in same column represent statistically significant data at $5 \%$. Normal control group; "Injury control group. Pj: injured control rats treated with oral pomegranate juice, PS: injured control rats treated with Spirulina extract, PJSP: injured control rats treated with the combination between oral pomegranate juice $90 \%$ and Spirulina extract $10 \%$.

\section{Oxidative stress markers}

Lipid peroxidation (MDA) is a process of autocatalysis and is natural consequence of cell death. It can induce inflammatory injury to peroxidative tissue (Bandyopadhyay et al., 1999).

In the current study, as shown in Table (4), plasma lipid peroxide concentrations were decreased in the treatment group relative to the liver injury group; the percentage of reduction was slightly lower in the PJSP group at $40.55 \%$ compared to the other treatment groups with $28.62 \%$ and $31.74 \% \%$ respectively in the PJ and SP groups. This finding is consistent with that of (Ahmed et al., 2011). At the other hand, glutathione improved in plasma in groups administered orally pomegranate juice (PJ) or spirulina extract (SP) and their combination (PJSP) by 19.9, 14.6 and 35.8 percent, respectively, relative to the injury group (IC). Ultimately, it could be noticed that the PJSP-consuming group had the largest substantial difference relative to the injury group. Attack GSH (reduced glutathione) may be the primary agent involved in redox protein thiol control (Sies, 1999). In studies performed by Vadiraja et al. (1998) Intraperitoneal administration of single dose of Spirulina phycocyanin to rats pretreated with $\mathrm{CCl}_{4}$ significantly decreased hepatotoxicity. Losses of microsomal cytochrome $\mathrm{P} 450$, aminopyrine- $\mathrm{N}$-demethylase, and glucose-6-phosphatase have been significantly reduced, thereby providing protection to liver enzymes by phycocyanin.

In a study conducted by Manal (2011), pomegranate juice significantly increased hepatic GST activity and preserved glutathione GSH levels even after treatment with $\mathrm{CCl}_{4}$. The mechanism of hepatoprotection by an extract of pomegranate against $\mathrm{CCl}_{4}$ toxicity may be due to restoration of $\mathrm{GSH}$ level. 
Table 4. Oxidative stress markers of different experimental groups

\begin{tabular}{|c|c|c|}
\hline Groups & MDA $(\mathrm{nmol} / \mathrm{ml})$ & GSH $(\mathrm{mg} / \mathrm{dl})$ \\
\hline NC $^{*}$ & $3.66 \pm 1.27^{\mathrm{b}}$ & $26.15 \pm 1.24^{\mathrm{b}}$ \\
\hline $\mathrm{IC}^{*}$ & $5.45 \pm 1.35^{\mathrm{a}}$ & $21.87 \pm 1.77^{\mathrm{c}}$ \\
\hline PJ & $3.89 \pm 0.21^{\mathrm{b}}$ & $26.23 \pm 1.13^{\mathrm{b}}$ \\
\hline SP & $3.72 \pm 0.66^{\mathrm{b}}$ & $25.07 \pm 2.21^{\mathrm{b}}$ \\
\hline PJSP & $3.24 \pm 0.44^{\mathrm{b}}$ & $29.71 \pm 3.11^{\mathrm{a}}$ \\
\hline
\end{tabular}

Data are mean \pm SE, $n=6$, uppercase letters in same column represent. Statistically significant data at $5 \%$. Normal control group; "Injury control group Pj: injured control rats treated with oral pomegranate juice, PS: injured control rats treated with Spirulina extract, PJSP: injured control rats treated with the combination between oral pomegranate juice $90 \%$ and Spirulina extract $10 \%$.

Table 5. Chemical composition of Spirulina platensis

\begin{tabular}{|c|c|}
\hline Component & $\mathrm{mg} / \mathrm{g}$ dry weight \\
\hline Total phenolics & $16.0 \pm 0.7$ \\
\hline Total carotenoids & $161 \pm 7.0$ \\
\hline Total flavonoids & $79.6 \pm 3.3$ \\
\hline
\end{tabular}

Data in Table 5 showed that the content of phytochemicals in Spirulina whereas the total carotenoids was higher followed by total flavonoids and total phenolics. Katsuya et al. (2007) showed that the total phenolics in Spirulina are five times higher than other species in blue- green algae. Also, Spirulina contains free carotenoids and carotenoid esters.

Table 6. UPLC-MSMS analysis of major components in methanolic extract of Spirulina platensis

\begin{tabular}{|c|c|c|c|}
\hline Main Components & Area $\%$ & $\mathrm{Rt}$ & $\mathrm{M}+$ \\
\hline$\beta$-Cryptoxanthin & 3.0 & 1.02 & 551 \\
\hline Zea-xanthine & 2.8 & 1.24 & 569 \\
\hline trans $\beta$ - Carotene & 57.3 & 2.94 & 536 \\
\hline cis $\beta$ - Carotene & 31.0 & 4.40 & 536 \\
\hline
\end{tabular}

Rt: retention time, $\mathrm{M}+$ : positive molecular ion

The chromatogram showed in Figure 1 Identify the major beaks at Rt of 2.92 and 4.4 min and comparison of the mass chart with National Institute of Standards and Technology (NIST) samples reveals that the major compounds in the extract are trans and cis- $\beta$-carotene. In current study, carotenoid extract analysis using UPLC-MS/MS in Spirulina platensis presented high levels of trans-and cis- $\beta$-carotene accompanied by $\beta$-cryptoxanthin and zeathanthin (Table 6). Carotenoids are one of the key pigment dependents who have assessed their nutritional and biological function, as per comprehensive research in field of algal-natural products. Spirulina platensis extract analysis revealed that it occurred same sequence $\beta$-carotene, zeaxanthin, myxoxanthophyll, chlorophyll. Other pigments have been known, such as pheophytin-like compounds, siphonin and astaxanthin along with other minor carotenoids (Mendiola et al., 2005). Similarly, Spirulina platensis displayed high $\beta$-carotene content 30 times higher than that contained in carrots (Yin et al., 2017). Carotenoids recorded antioxidant properties as active compounds but their efficacy varies between source to source (Sallam et al., 2017; Cipolatti et al., 2019; El-Beltagi et al., 2018, 2019a-b). Past studies have been conducted on impact of naturally present and food-approved carotenoids (e.g. B-carotene, canthaxanthin) on single oxidation of vegetable oils (Panek et al., 2001). Single-oxygen quenching levels of food-approved carotenoids increased with numbers of conjugated double carotenoid bonds (Jung and Min, 1991; Hamed et al., 2019). 


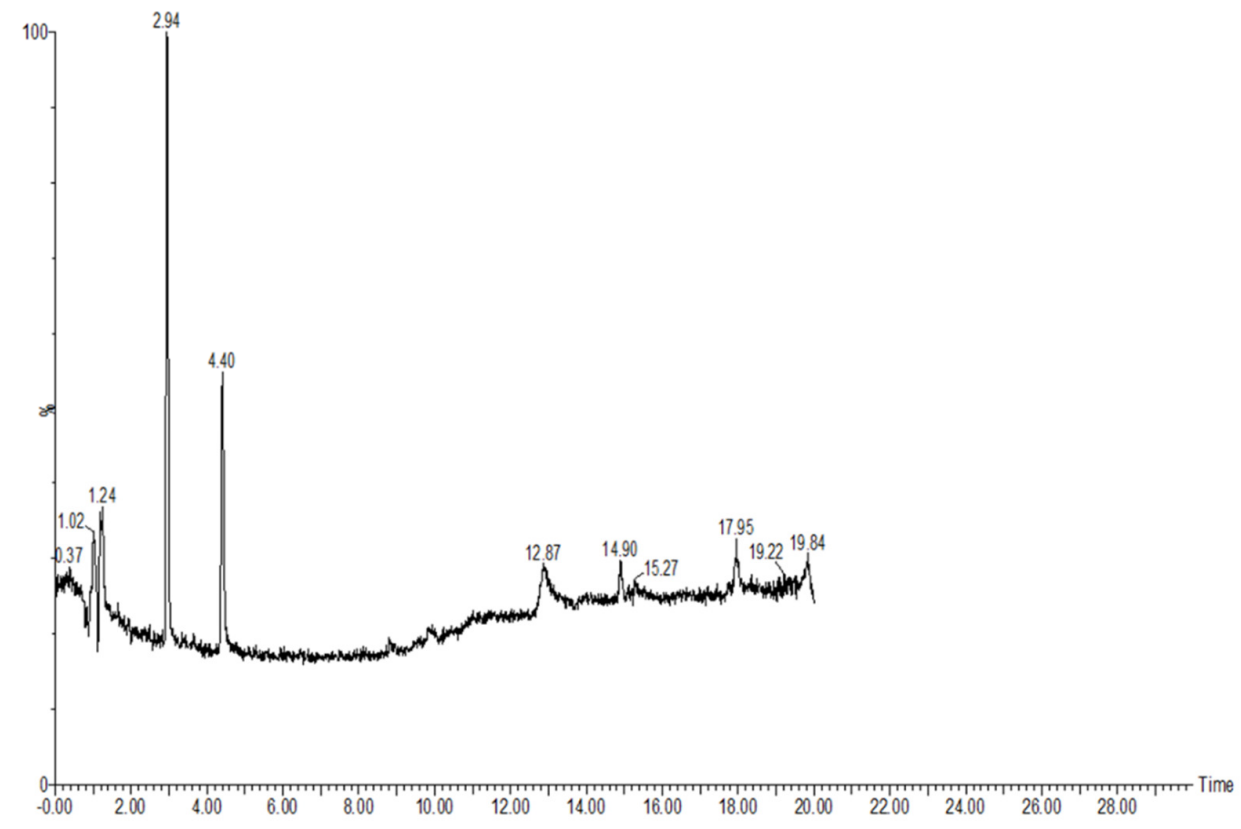

Figure 1. Chromatogram of carotenoids analysis by UPLC MS/MS

Effect of carotenoids extract from Spirulina platensis on tumor cell lines

In this part of study, crude extract of Spirulina carotenoids assayed to human carcinoma cell lines to evaluate its activity as anticancer which add value to the dietary Spirulina. Data provided in Table 7 and illustrated in Figure 2 stated that a dose dependent of carotenoids extract from Spirulina platensis and reduction the surviving fraction of intestinal followed by liver and finally colon tumor cell lines. Phycocyanobilin (PCB) and chlorophylls are among other potentially bioactive substances of particular interest due to their structural similarity to bilirubin, potent antioxidant, atheroprotective, anti-proliferative agent (Konícková et al., 2014).

The cytotoxicity exhibited by Spirulina extract to cancer cell lines might be due to the presence of phytopigments (carotenoids, chlorophyll, phycocyanin) as well as polysaccharides that were reported previously as constituents of the extract. So crude extracts of Spirulina can be used as a source to develop anticancer drugs (Hernandez et al., 2017).

Table 7. Lc $c_{50}$ of spirulina carotenoids extract in tumor cell lines of different types of cancer

\begin{tabular}{|c|c|}
\hline Tumor cell line & LC50 ug/ml \\
\hline Colon (HCT116) & 21.8 \\
\hline Liver (HEPG2) & 14 \\
\hline Intestinal (CACO) & 11.3 \\
\hline
\end{tabular}



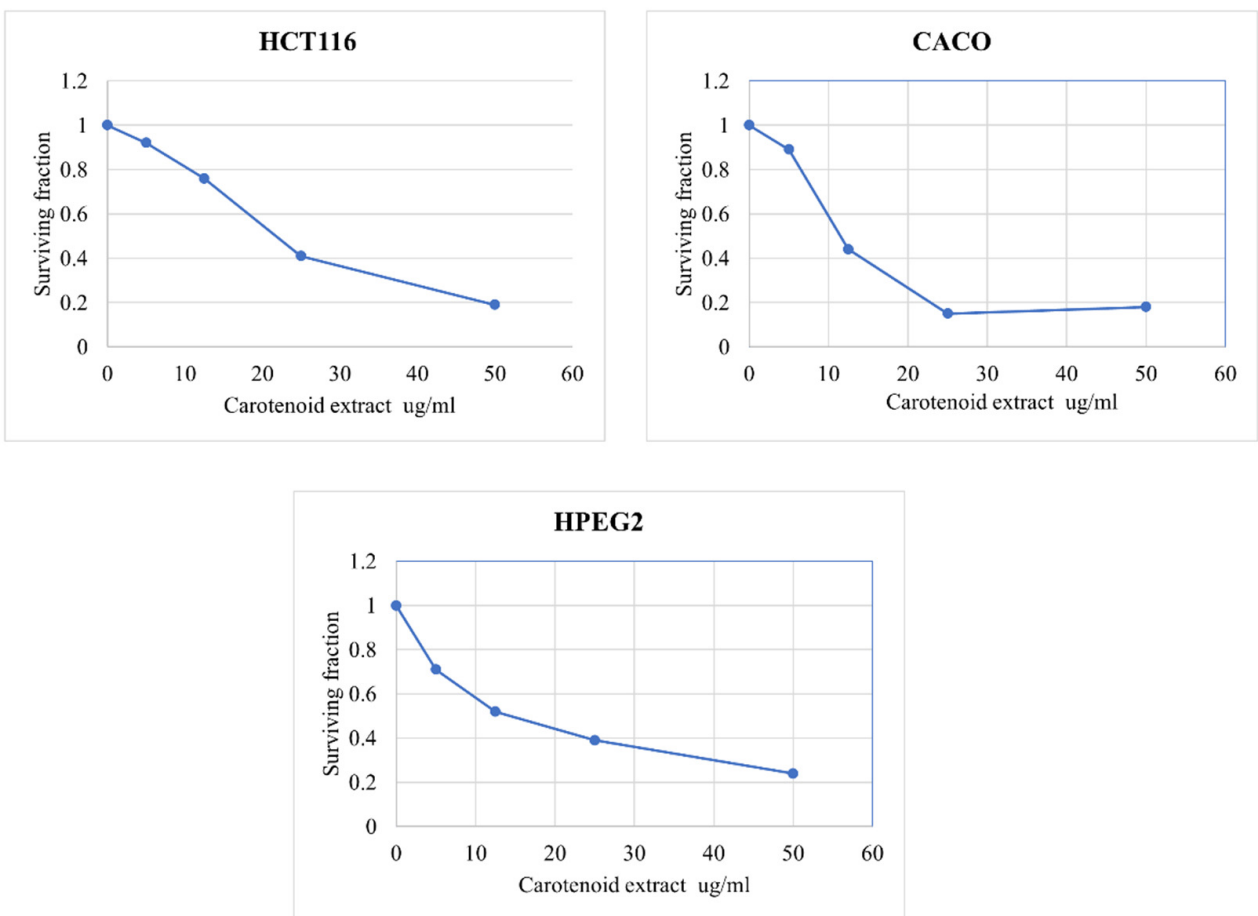

Figure 2. The relationship between surviving fraction and concentrations of carotenoid extracts of Spirulina platensis for treating (HCT116), (HEPG2) and (CACO) cell lines

Spirulina bilirubin's anticancer activity has been attributed to its effects on mitochondria and intracellular signaling (Keshavan et al., 2004; Ollinger et al., 2007). Bilirubin has also been shown to be a commonly used protein phosphorylation inhibitor. Previous study showed that the therapeutics tested exerted strong antioxidant effects with substantial reductions in ROS levels of mitochondrial reactive oxygen species, which strengthened the overall cell redox status as shown by observed improvement in parameters of redox glutathione (Konícková et al., 2014). These results tend to be related to bilirubin's inhibitory effects on superoxide formation and the mitochondrial metabolism in general (Nakamura et al., 1987). It has also been proposed that pyrrole groups of bilirubin present in our compounds interact with NADH at active mitochondrial dehydrogenase sites suggesting possible mechanisms for these effects. Spirulina aqueous extract had greater effect on HepG2 and HSC than chlorella. Spirulina's LC50 value for HepG2 was 60 at complete phenolic concentration (Li-Chen et al., 2005). It also had significant cytotoxic effect of on human acute leukemia Kasumi-1, chronic myelogenous leukemia K-562 and e human lung cancer A549 cell lines (Hernandez et al., 2017; Czerwonka et al., 2018). In addition, Spirulina platensis water extracts showed antiproliferative properties against breast cancer adenocarcinoma cell line (MCF-7) and mice intestine carcinoma cell line (L20B) suggesting that new promising anticancer natural products from blue-green algae are possible (Fayyad et al., 2019). The Spirulina platensis derived phycocyanin pigments have more active functional groups with potential anticancer, anti-diabetic and anti-inflammatory action and it could be considered as an alternate functional food for food and drug industry (Prabakaran et al., 2020). 


\section{Conclusions}

Based on results obtained, it was assumed that conventional and common dietary Spirulina and pomegranate juice had antioxidant activity and significantly reduced hepatic damage caused by $\mathrm{CCl}$, and that the combination of both Spirulina and pomegranate juice did not significantly affect the hepatoprotective properties of Spirulina and pomegranate juice, meaning that it could be used as a therapeutic natural and benefitted beverage. In addition, Spirulina carotenoids showed anti-cancer activity in the liver, colon and intestine tumor cell lines.

\section{Authors' Contributions}

Conceptualization, I.S.A. and K.MA.R.; Methodology, K.MA.R.; Formal analysis, F.D., H.S.E., I.S.A. and K.MA.R.; Funding acquisition, F.D., H.S.E. and K.MA.R.; Investigation, F.D., H.S.E. and K.MA.R.; Resources, I.S.A. and K.MA.R.; Data curation, H.S.E., I.S.A. and K.MA.R.; Project administration, F.D., H.S.E., A.M.H. and E.AH.S.E., Writing-original draft preparation, I.S.A. and K.MA.R.; Software, H.S.E. and K.MA.R.; Supervision, H.S.E. and K.MA.R.; Validation, I.S.A. and K.MA.R.; Visualization, H.S.E. and K.MA.R.; Writing-review and editing, F.D., H.S.E., I.S.A. and K.MA.R.; All authors have read and agreed to the published version of the manuscript.

Ethical approval (for researches involving animals or humans)

Ethical approval, for all the practiced experimental protocols, was obtained from Medical Research Ethics Committee, National Research Center (NRC-MREC; number, 20/150) according to Egyptian Network of Research Ethics Committee (ENREC) regulations.

\section{Acknowledgements}

Authors extend their appreciation to Deputyship for Research \& Innovation, Ministry of Education in Saudi Arabia for funding this research work through the project number IFT20177.

\section{Conflict of Interests}

The authors declare that there are no conflicts of interest related to this article.

\section{References}

Abd El-Maksoud AA, Abd El-Ghany IH, El-Beltagi HS, Anankanbil S, Banerijee C, Petersen SV, ... Guo Z (2018). Adding functionality to milk-based protein: Preparation, and physicochemical characterization of $\beta$-lactoglobulinphenolic conjugates. Food Chemistry 241:281-289. https://doi.org10.1016/j.foodchem.2017.08.101

Abdel-Salam AM, Ashoush IS, Hamad EM Mousa HM (2015). Potential protective effect of fermented camel milk containing probiotic, prebiotic and synbiotic against lead and cadmium-intoxicated male rats. International Journal of Humanities, Arts, Medicine and Sciences (BEST: IJHAMS) 3(11):131-148. 
Abdel-Rahim EA, El-Beltagi HS (2010). Constituents of apple, parsley and lentil edible plants and their therapy treatments for blood picture as well as liver and kidney functions against lipidemic disease. Electronic Journal of Environmental, Agricultural and Food Chemistry 9(6):1117-1127.

Abdel-Rahim EA, El-Beltagi HS, Romela RM (2013). White bean seeds and pomegranate peel and fruit seeds as hypercholesterolemic and hypolipidemic agents in albino rats. Grasas y Aceites 64(1):50-58. https://doi.org/10.3989/gya.095412

Abe K, Hattori H, Hirano M (2007). Accumulation and antioxidant activity of secondary carotenoids in the aerial microalga Coelastrella striolata var. multistriata. Food Chemistry 100:656-661. https://doi.org/10.1016/j.foodchem.2005.10.026

Ahmed SG, Yasser AK, Aziza AE, Sherif RM, Nabila SH, Mosaad AA (2011). Antioxidant activity and hepatoprotective effects of whey protein and Spirulina in rats. Nutrition 27:582-589. https://doi.org/10.1016/j.nut.2010.04.002

Akladious SA, Mohamed HI (2017). Physiological role of exogenous nitric oxide in improving performance, yield and some biochemical aspects of sunflower plant under zinc stress. Acta Biologica Hungarica 68(1):101-114. https://doi.org/10.1556/018.68.2017.1.9

Akram A, Ulfat O, Marwa Y, Mary G, Mary AL, Nazlin H (2016). Antioxidant activity of pomegranate juice and punicalagin. Natural Science 8:235-246. https://doi.org/10.4236/ns.2016.86028

Al-Olayan EM, El-Khadragy MF, Metwally DM, Abdel Moneim AE (2014). Protective effects of pomegranate (Punica granatum) juice on testes against carbon tetrachloride intoxication in rats. BMC Complementary and Alternative Medicine 14:164. https://doi.org/10.1186/1472-6882-14-164

Aly AA, Mansour MTM, Mohamed HI, Abd-Elsalam KA (2012a). Examination of correlations between several biochemical components and powdery mildew resistance of flax cultivars. Plant Pathology Journal 28(2):149155. https://doi.org/10.5423/PPJ.2012.28.2.149

Asrani SK, Devarbhavi H, Eaton J, Kamath PS. Burden of liver diseases in the world. Journal of Hepatology 70:151-171. https://doi.org/10.1016/j.jhep.2018.09.014

Aviram M, Dornfeld L, Rosenblat M, Volkova N, Kaplan M, Coleman R (2000). Pomegranate juice consumption reduces oxidative stress, atherogenic modifications to LDL, and platelet aggregation: studies in humans and in atherosc-lerotic apolipoprotein E-deficient mice. American Journal of Clinical Nutrition 71:1062-1076. https://doi.org/10.1093/ajcn/71.5.1062

Balasundram, N, Sundram K, Samman S (2006). Phenolic com-pounds in plants and agri-industrial by-products: anti-oxidant activity, occurrence, and potential uses. Food Chemistry 99:191-203. https://doi.org/10.1016/j.foodchem.2005.07.042

Bandyopadhyay U, Das D, Banerjee KR (1999). Reactive oxygen species: Oxidative damage and pathogenesis. Current Science 77:658-66.

Bernal J, Mendiola JA, Ibáñez E, Cifuentes A (2011). Advanced analysis of nutraceuticals. Journal of Pharmaceutical and Biomedical Analysis 55:758-774. https://doi.org/10.1016/j.jpba.2010.11.033

Beutler E, Duron O, Kelly BM (1963). Improved method for the determination of blood glutathione. Journal of Laboratory and Clinical Medicine 61:882-888.

Brand-Williams W, Cuvelier ME, Berset C (1995). Use of a free radical method to evaluate antioxidant activity. LWT Food Science and Technology 28:25-30. https://doi.org/10.1016/S0023-6438(95)80008-5

Cipolatti EP, Remedi RD, Sá CD, Rodrigues AB, Ramos JMG, Burkerta CAV, ... Burkert JFD (2019). Use of agroindustrial byproducts as substrate for production of carotenoids with antioxidant potential by wild yeasts. Biocatalysis and Agricultural Biotechnology 20:101208

Chaterrjee TK (2000). Medicinal plants with hepatoprotective properties. Herbal options. Books and Applied Allied (P) Ltd, Calcutta, pp13.

Czerwonka A, Kaławaj K, Sławińska-Brych A, Lemieszek MK, Bartnik M, Wojtanowski KK, ... Rzesk W (2018). Anticancer effect of the water extract of a commercial Spirulina (Arthrospira platensis) product on the human lung cancer A549 cell line. Biomedicine \& Pharmacotherapy 106:292-302. https://doi.org/10.1016/j.biopha.2018.06.116

Dartsch PC (2008). Antioxidant potential of selected Spirulina platensis preparations. Phytotherapy Research 22(5):627633. https://doi.org/10.1002/ptr.2310

de Cruz CR, Lubrano A, Gatlin DM (2018). Evaluation of microalgae concentrates as partial fishmeal replacements for $\begin{array}{lllll}\text { hybrid striped } \quad \text { bass } & \text { Morone } & \text { 493:130-136. }\end{array}$ https://doi.org/https://doi.org/10.1016/j.aquaculture.2018.04.060 
Djeridane A, Yousfi M, Nadjemi B, Boutassouna D, Stocker P, Vidal N (2006). Antioxidant activity of some Algerian medicinal plants extracts containing phenolic compounds. Food Chemistry 97:654-660. https://doi.org/10.1016/j.foodchem.2005.04.028

El-Baz FK, El-Senousy WM, El-Sayed AB, Kamel MM (2013) In vitro antiviral and antimicrobial activities of Spirulina platensis extract. Journal of Applied Pharmaceutical Science 3:52-56, http://dx.doi.org/10.7324/JAPS.2013.31209

El-Beltagi HS, Mohamed HI, Safwat G, Megahed BMH, Gamal M (2018). Evaluation of some chemical constituents, antioxidant, antibacterial and anticancer activities of Beta vulgaris L. root. Fresenius Environmental Bulletin 27(9):6369-6378.

El-Beltagi HS, Mohamed HI, Elmelegy AA, Eldesoky SE, Safwat G (2019a). Phytochemical screening, antimicrobial, antioxidant, anticancer activities and nutritional values of cactus (Opuntia ficus indicia) pulp and peel. Fresenius Environmental Bulletin 28(2A):1534-1551.

El-Beltagi HS, Mohamed HI, Safwat G, Gamal M, Megahed BMH (2019b). Chemical composition and biological activity of Physalis peruviana L. Gesunde Pflanzen 71:113-122. https://doi.org/10.1007\%2Fs10343-019-00456-8

Faria A, Monteiro R, Mateus N, Azevedo I, Calhau C (2007). Effect of pomegranate (Punica granatum) juice intake on hepatic oxidative stress. European Journal of Nutrition 46:271-278. https://doi.org/10.1007/s00394-0070661-Z

Fayyad RJ, Ali ANM, Dwaish AS, Abed Al- Abboodi AK (2019). Anticancer activity of Spirulina platensis methanolic extracts against L20B and MCF7 human cancer cell lines. Plant Archives 19(1):1419-1426.

Feltl L, Pacákováa V, Stulika K, Volka K (2005). Reliability of carotenoid analyses: a review. Current Analytical Chemistry 1:93-102.

Finamore A, Palmery M, Bensehaila S, Peluso I (2017). Antioxidant, immunomodulating, and microbial-modulating activities of the sustainable and ecofriendly Spirulina. Oxidative Medicine and Cellular Longevity 2017:3247528. https://doi.org/10.1155/2017/3247528

García-Martínez D, Rupérez FJ, Ugarte P, Barbas C (2007). Tocopherol fate in plasma and liver of streptozotocin-treated rats that orally received antioxidants and Spirulina extracts. International Journal for Vitamin and Nutrition Research 77(4):263-271. https://doi.org/10.1024/0300-9831.77.4.263

Hamed MM, Abd El-Mobdy MA, Kamel MT, Mohamed HI, Bayoumi AE (2019). Phytochemical and biological activities of two asteraceae plants Senecio vulgaris and Pluchea dioscoridis L. Pharmacology Online 2:101-121.

Hanson CJ, Bootman MD, Distelhorst CW, Maraldi T, Roderick HL (2008). The cellular concentration of Bcl-2 determines its pro- or anti-apoptotic effect. Cell Calcium 44(3):243-258. https://doi.org/10.1016/j.ceca.2007.11.014

Helmi A, Mohamed HI (2016). Biochemical and ulturasturctural changes of some tomato cultivars to infestation with Aphis gossypii Glover (Hemiptera: Aphididae) at Qalyubiya, Egypt. Gesunde Pflanzen 68:41-50. https://doi.org/10.1007/s10343-016-0361-9

Hernandez FYF, Khandual S, Lopez IGR (2017). Cytotoxic effect of Spirulina platensis extracts on human acute leukemia Kasumi-1 and chronic myelogenous leukemia K-562 cell lines. Asian Pacific Journal of Tropical Biomedicine 7(1):9-14. https://doi.org/10.1016/j.apjtb.2016.10.011

Ismail MF, Ali DA, Fernando A, Abdraboh ME, Gaur RL, Ibrahim WM, ... Ouhtit A (2009). Chemoprevention of rat liver toxicity and carcinogenesis by Spirulina. International Journal of Biological Sciences 5(4):377-387. https://doi.org/10.7150/ijbs.5.377

Jaiswal V, DerMarderosian A, Porter JR (2010). Anthocyanins and polyphenol oxidase from dried arils of pomegranate (Punica granatum L.). Food Chemistry 118(1):11-16.

Jung MY, Min DB (1991). Effect of quenching mechanisms of carotenoids on the photosensitized oxidation of soybean oil. Journal of the American Oil Chemists Society 68:653-658. https://doi.org/10.1007/BF02662288

Karan M, Vasisht K, Handa SS (1999). Antihepatotoxic activity of Swertia chirata on carbontetrachloride induced hepatotoxicity in rats. Phytotherapy Research 13:24-30. https://doi.org/10.1002/(SICI)10991573(199902)13:1<24::AID-PTR378>3.0.CO;2-L

Karadeniz A, Cemek M, Simsek N (2009). The effects of Panax ginseng and Spirulina platensis on hepatotoxicity induced by cadmium in rats. Ecotoxicology and Environmental Safety 72(1):231-235. https://doi.org/10.1016/j.ecoenv.2008.02.021 
Keshavan P, Schwemberger SJ, Smith DLH, Babcock GF, Zucker SD (2004). Unconjugated bilirubin induces apoptosis in colon cancer cells by triggering mitochondrial depolarization. International Journal of Cancer 112:433-45. https://doi.org/10.1002/ijc.20418

Kew MC (2002). Epidemiology of hepatocellular carcinoma. Toxicology 181-182:35-38. https://doi.org/10.1016/S0300-483X(02)00251-2

Konícková R, Vanková K, Vaníková J, Vánová K, Muchová L, Subhanová I... Vítek L (2014). Anticancer effects of bluegreen alga Spirulina platensis, a natural source of bilirubin-like tetrapyrrolic compounds. Annals of Hepatology 13(2):273-283.

Lansky EP (2006). Beware of pomegranates bearing 40\% ellagic acid. Journal of Medicinal Food 9:119-22. https://doi.org/10.1089/jmf.2006.9.119

Marín L, Miguélez EM, Villar CJ, Lombó F (2015). Bioavailability of dietary polyphenols and gut microbiota metabolism: antimicrobial properties. BioMed Research International 2015:1-18. https://doi.og/10.1155/2015/905215

Małgorzata K, Ewa I, Marek M, Małgorzata E, Katarzyna M, Jodynis-Liebert J (2009). Protective effect of red beetroot against carbon tetrachloride- and n-nitrosodiethylamine-induced oxidative stress in rats. Journal of Agricultural and Food Chemistry 57:2570-2575. https://doi.org/10.1021/jf803315d

Manal FE (2011). Hepatoprotective role of the pomegranate (Punica granatum) juice on carbon tetrachloride-induced oxidative stress in rats. African Journal of Biological Science 7(1):135-149.

Marzorati S, Schievano A, Idàb A, Verotta L (2020). Carotenoids, chlorophylls and phycocyanin from Spirulina: supercritical CO2 and water extraction methods for added value products cascade. Green Chemistry 22:187196. https://doi.org/10.1039/c9gc03292d

Maskan M (2006). Production of pomegranate (Punica granatum L.) juice concentrate by various heating methods: color degradation and kinetics. Journal of Food Engineering 72:218-224. https://doi.org/10.1016/j.jfoodeng.2004.11.012

Matthaiou CM, Goutzourelas N, Stagos D, Sarafoglou E, Jamurtas A, Koulocheri SD, ... Kouretas D (2014). Pomegranate juice consumption increases GSH levels and re-duces lipid and protein oxidation in human blood. Food and Chemical Toxicology 73:1-6. https://doi.org/10.1016/j.fct.2014.07.027

Mendiola JA, Marín FR, Hernandez S, Arredondo BO, Señoráns FJ, Ibañez E, Reglero G (2005). Characterization via liquid chromatography coupled to diode array detector and tandem mass spectrometry of supercritical fluid antioxidant extracts of Spirulina platensis microalga. Journal of Separation Science 28:1031-1038. https://doi.org/10.1002/jssc.200500035

Mohamed HI, Akladious SA (2017). Changes in antioxidants potential, secondary metabolites and plant hormones induced by different fungicides treatment in cotton plants. Pesticide Physiology and Biochemistry 142:117-122. https://doi.org/10.1016/j.pestbp.2017.04.001

Nagao A (2014). Bioavailability of dietary carotenoids: intestinal absorption and metabolism. Japan Agricultural Research Quarterly 48(4):385-391. https://doi.org/10.6090/jarq.48.385

Nakamura H, Uetani Y, Komura M, Takada S, Sano K, Matsuo T (1987). Inhibitory action of bilirubin on superoxide production by polymorphonuclear leukocytes. Biology of the Neonate 52:273-278. https://doi.org/10.1159/000242720

Nirwane A, Patil R (2012). Effect of Punica granatum seeds on doxorubicin-induced hepatotoxicity in Wistar Rats. Journal of Pharmacy Research 5:4625-4628.

Ohkawa H, Ohishi N, Yagi K (1979). Assay for lipid peroxides in animal tissues by thiobarbituric acid reaction. Analytical Biochemistry 95:351-358. https://doi.org/10.1016/0003-2697(79)90738-3

Ollinger R, Kogler P, Troppmair J, Hermann M, Wurm M, Drasche A, ... Margreiter R (2007). Bilirubin inhibits tumor cell growth via activation of ERK. Cell Cycle 6:3078-3085.

Panek J, Fantova L, Trojakova L, Reblova Z, Pokorny J (2001). Effectiveness of natural antioxidants in sunflower oil. Special Publication- Royal Society of Chemistry 269:371-374.

Prabakaran G, Sampathkumar P, Kavisri M, Moovendhan M (2020). Extraction and characterization of phycocyanin from Spirulina platensis and evaluation of its anticancer, antidiabetic and antiinflammatory effect. International Journal of Biological Macromolecules 153:256-263. https://doi.org/10.1016/j.ijbiomac.2020.03.009

Reeves PG, Nielsen FH, Fahey Jr, GC (1993). AIN-93 purified diets for laboratory rodents: final report of the American Institute of Nutrition ad hoc writing committee on the reformulation of the AIN-76A rodent diet. Journal of Nutrition 123(11):1939-1951. https://doi.org/10.1093/jn/123.11.1939 
Reitman S, Frankel S (1957). A colorimetric method of the determination of plasma glutamic oxaloacetic and glutamic pyruvic transaminases. American Journal of Clinical Pathology 28:56-63. https://doi.org/10.1093/ajcp/28.1.56

Remziye AK, Sait P, Ahmet C, Nuray B, Saadet DS (2013). Protective effect of Spirulina platensis enriched in phenolic compounds against hepatotoxicity induced by CCl4. Food Chemistry 141:1972-1979. https://doi.org/10.1016/j.foodchem.2013.04.107

Rechter S, Konig T, Auerochs S, Thulke S, Walter H, Dornenburg HD, Walter C, Marschall M (2006). Antiviral activity of Arthrospira-derived spirulan-like substances. Antiviral Research 72:197-206, https://dx.doi.org/10.1016/j.antiviral.2006.06.004

Rosenblat M, Hayek T, Aviram M (2006). Antioxidative effects of pomegranate juice (PJ) consumption by diabetic pa-tients on serum and on macrophages. Atherosclerosis 187:363-371. https://doi.org/10.1016/j.atherosclerosis.2005.09.006

Rouanet JM, Kelly D, Daniele DR, Cyril A, Gina B, Jean-Paul C, ... Alan C (2010). Berry juices, teas, antioxidants and the prevention of atherosclerosis in hamsters. Food Chemistry 118:266-271. https://doi.org/10.1016/j.foodchem.2009.04.116

Sadia H, Akter QS, Afroz R, Siddiqua T (2016). Effect of Punica granatum (Pomegranate) on serum ALT and AST in carbon tetrachloride induced liver damage in Wistar albino rats. Journal of Bangladesh Society of Physiologist 11(1):23-28.

Sallam AE, Mansour AT, Srour TM, Goda AMA (2017). Effects of different carotenoid supplementation sources with or without sodium taurocholate on growth, feed utilization, carotenoid content and antioxidant status in fry of the European seabass, Dicentrarchus labrax. Aquaculture Research 48(7):3848-3858.

Sanoner P, Guyot S, Marnet N, Molle D, Drilleau JF (1999). Polyphenol profiles of French cider apple varieties (Malus domestica sp.). Journal of Agricultural and Food Chemistry 47:4847-4853. https://doi.org/10.1021/jf990563y

SAS (2003). SAS/ Stat Users Guide: Statistics, System for Windows, version 4.10 (release 8.01 TS level 01M0), SAS Inst, Inc. Cary, North Carolina, USA.

Seeram NP, Adams LS, Henning SM (2005). In vitro antiproli-ferative, apoptotic and antioxidant activities of punicalagin, ellagic acid and a total pomegranate tannin extract are enhanced in combination with other polyphenols as found in pomegranate juice. Journal of Nutritional Biochemistry 16:360-367. https://doi.org/10.1016/j.jnutbio.2005.01.006

Serban M-C, Sahebkar A, Dragan S, Stoichescu-Hogea G, Ursoniu S, Andrica F, Banach M (2016). A systematic review and meta-analysis of the impact of Spirulina supplementation on plasma lipid concentrations. Clinical Nutrition 35(4):842-851. https://doi.org/10.1016/j.clnu.2015.09.007

Sies H (1999). Glutathione and its role in cellular functions. Free Radical Biology and Medicine 27:916-21. https://doi.org/10.1016/s0891-5849(99)00177-X

Sharma MK, Sharma A, Kumar A, Kumar M (2007). Spirulina fusiforms provides protection against mercuric chloride induced oxidative stress in Swiss albino mice. Food and Chemical Toxicology 45:2412-2419. https://doi.org/10.1016/j.fct.2007.06.023

Skehan P, Storeng R, Scudiero D, Monks A, McMahon J, Vistica D, ... Boyd MR (1990). New colorimetric cytotoxicity assay for anticancer-drug screening. Journal of The National Cancer Institute 82(13):1107-1112. https://doi.org/10.1093/jnci/82.13.1107

Soni RA, Sudhakar K, Rana R (2017). Spirulina-from growth to nutritional product: A review. Trends in Food Science and Technology 69:157-171. https://doi.org/https://doi.org/10.1016/j.tifs.2017.09.010

Subagio A, Morita N, Sawada S (1996). Carotenoids and their fatty acid esters in banana peel. Journal of Nutritional Science and Vitaminology 42:553-566. https://doi.org/https://doi.org/10.3177/jnsv. 42.553

Subramonium A, Pushpangadan P (1999). Development of phytomedicines for liver diseases. Indian Journal Pharmacology 31:166-175.

Surh YJ (1999). Molecular mechanisms of chemopreventive effects of selected dietary and medical phenolic substances. Mutation Research 428(1-2):305-327. https://doi.org/10.1016/s1383-5742(99)00057-5

Vadiraja BB, Gaikwad NW, Madhyastha KM (1998). Hepato-protective effect of C- Phycocyanin: protection for carbon tetrachloride and pulegeon mediated hepato-toxicity in rats. Biochemical and Biophysical Research Communications 249(2):428-431. https://doi.org/10.1006/bbrc.1998.9149

Ward FM, Daly MJ (1999). Hepatic Disease. In: Clinical Pharmacy and Therapeutics Walker R, Edwards C (Eds). Churchill Livingstone, New York, pp 195-212. 
Wu LC, Ho JA, Shieh MC, Lu IW (2005). Antioxidant and antiproliferative activities of Spirulina and Chlorella water extracts. Journal of Agricultural and Food Chemistry 53(10):4207-4212. https://doi.org/10.1021/jf0479517

Yin C, Daoust K, Young A, Tebbs E, Harper D (2017). Tackling community undernutrition at Lake Bogoria, Kenya: the potential of Spirulina (Arthrospira fusiformis) as a food supplement. African Journal of Food, Agriculture, Nutrition and Development 17:11603-11615. https://doi.org/10.18697/ajfand.77.15440

Yoshikawa N, Belay A (2008). Single-laboratory validation of a method for the determination of c-phycocyanin and allophycocyanin in Spirulina (Arthrospira) supplements and raw materials by spectrophotometry. Journal of AOAC International 91(3):524-529.

Zhang P, Omaye ST (2001). Antioxidant and prooxidant roles for beta-carotene, alpha-tocopherol and ascorbic acid in human lung cells. Toxicology in Vitro 15(1):13-24. https://doi.org/10.1016/s0887-2333(00)00054-0
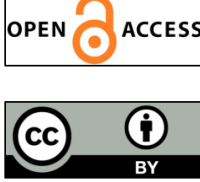

The journal offers free, immediate, and unrestricted access to peer-reviewed research and scholarly work. Users are allowed to read, download, copy, distribute, print, search, or link to the full texts of the articles, or use them for any other lawful purpose, without asking prior permission from the publisher or the author.

License - Articles published in Notulae Botanicae Horti Agrobotanici Cluj-Napoca are Open-Access, distributed under the terms and conditions of the Creative Commons Attribution (CC BY 4.0) License. (c) Articles by the authors; UASVM, Cluj-Napoca, Romania. The journal allows the author(s) to hold the copyright/to retain publishing rights without restriction. 